REVIEW

\title{
What should a suspended doctor do when his actions could save a patient's life?
}

\section{J A D Stewart}

Postgrad Med J 2003;79:204-205

Suspension from duty is becoming an increasing threat for medical practitioners. While under suspension a doctor may, in extreme circumstances, find themselves in a difficult legal dilemma as to their duty of care towards others. A suspended doctor may risk litigation if they are unaware of the legal ramifications of their unusual circumstances. The following article outlines the legal situation as it applies to England and Wales.

\section{THE SUSPENDED DOCTOR}

Being "suspended from duty" is a phrase that must strike fear into the hearts of most medical practitioners. Unfortunately, it is not an uncommon occurrence as NHS trusts increasingly seek to protect their patient's and their own reputations from an ever litigious and critical public. A recent article in the medical press suggested that at the time of writing, approximately 100 doctors were under suspension from the NHS.'

Suspension can imply one of two things. Either the doctor has been suspended from the medical register by the General Medical Council (GMC) and therefore cannot function as a medical practitioner for the duration of that suspension, or the trust has suspended the doctor from practising within their organisation pending an investigation, but he or she remains fully registered with the GMC.

The former situation is relatively straightforward as it effectively means that the doctor owes no more than the "normal" duty of care (as a member of the public) to another individual. In law there is no general legal duty of care to rescue another. An exception to this is if the rescuer is the parent of a child who requires rescuing, or someone who in law owes a duty to rescue an individual (for example doctors in some, but not all, circumstances).

The latter situation raises more problematic questions. If a doctor is suspended by his trust but is still on the medical register, then he is by definition still a licensed medical practitioner, albeit

Correspondence to: Dr J A D Stewart, Department of Integrated Medicine, Glenfield Hospital, Groby Road Leicester LE3 9QP, UK james.stewart@uhl-tr.nhs.uk

Submitted

29 January 2003

Accepted

31 January 2003 one prohibited from his usual place of work. What are his duties?

\section{DUTY OF CARE}

To answer this it is important to first define a legal duty of care, and its relevance in the tort of negligence. It is established legal doctrine that a duty of care arises between an individual and another person when the first individual has foresight that his actions may cause damage, that there is sufficient legal proximity between the parties and that it is fair, just, and reasonable to impose the duty in all the circumstances. ${ }^{2}$

An individual will be guilty of civil negligence if it is established that a duty of care existed, that the duty was breached and, on the balance of probabilities, the breach caused the damage complained of. ${ }^{3}$ If these criteria are fulfilled financial compensation will be payable. In criminal law, if a breach of a duty of care were to result (beyond reasonable doubt) in a death, then the individual would be found guilty of criminal negligence and therefore manslaughter. ${ }^{4}$ Thus establishing a duty of care is the bedrock on which both civil and criminal negligence cases rest.

As previously mentioned there is no general legal duty to rescue. Therefore a doctor (suspended or not) will not be held legally liable for driving past an accident without stopping (as long as he did not cause the accident in the first place). The exception to this would be a general practitioner (GP) who while driving home through his practice area comes across an accident victim. By virtue of s4(1)h of the NHS (General Medical Services) Regulations 1992 he has a legal obligation to treat that patient if "requested". However should the doctor have been suspended from duty by the relevant health authority then this duty will no longer exist.

\section{CIRCUMSTANCE}

It is not without the bounds of reason, or possibility, that a suspended doctor may find themselves in a situation which tests their duty of care. If one were to imagine the scenario whereby a suspended GP or hospital doctor is at a football match and the person in front of them collapses then a difficult issue arises. What should the doctor do? Of course the doctor need not act at all. He need not even respond to a request over the public address system for a doctor. He has no legal duty of care toward them. However, if he should respond, then he immediately establishes a legal duty of care toward the patient. He must then take pains to ensure that he does not make matters worse, as he is at risk of an action for negligence should he do so. This may appear, at first sight, to be logical. But what if (as part of his resuscitation) he attempts to insert a makeshift chest drain, knowing that the reason for his suspension from work was related to a negligent act involving a chest drain? Should our football spectator then be unlucky enough to suffer a serious

Abbreviations: GMC, General Medical Council; GP, general practitioner 
complication resulting from the chest drain insertion, he might subsequently argue that the attending doctor had breached his duty of care by undertaking a hazardous procedure for which he has subsequently been proved not to be able to perform to an adequate standard.

But what specifically, of hospital practitioners? It is often the case that hospital practitioners when suspended are then excluded from their workplace. Thus their duty to rescue becomes that of the general public. But consider the following. A suspended cardiologist (who has been suspended for incompetent resuscitation techniques) is standing in a shop queue directly behind a person who he knows has a severe cardiomyopathy and is on the waiting list for insertion of an implantable defibrillator. He has been engaged in conversation with this patient when they suddenly collapse. The cardiologist immediately suspects a malignant arrythmia. What should he do? At first sight it would seem that he has no legal duty to act. However, it might be argued that he has sufficient legal proximity to the patient and forseeability of the damage which may be caused by a failure to act that despite his suspension he is under a duty of care to rescue the patient. If he should decide to walk away from the situation and await an ambulance to resuscitate the patient, who because of the delay suffers cerebral anoxia, it is possible that he could be found to have breached his duty of care and hence negligence may be established. Bizarrely, however, if he immediately attempted resuscitation and the patient developed brain damage due to incompetent resuscitation technique, an action for negligence may then arise by virtue of the fact that the cardiologist had been suspended pending an investigation into his competence to resuscitate. As such, it may be argued he should not have made the situation worse through inept intervention.

We can change the circumstances in order to complicate the scenario further and strengthen the argument that he has a duty of care. Imagine now that as part of his suspension he has been told he must not enter the hospital. However, his son is ill and has been admitted to the paediatric wards. While visiting his son, the suspended cardiologist comes across the same patient, collapsed in the lifts. He is presently suspended from duty and technically banned from clinical practice within the hospital. What are his duties now? Again it might be argued that he has no duty to rescue, and that he is simply present as a relative to a patient and not a doctor. However, he knows this patient very well and usually treats him in his clinic within this hospital. He knows where the nearest resuscitation trolley is kept. Does he therefore have sufficient legal proximity to establish a duty of care? He must almost certainly

\section{Key points}

- There is no general legal duty to rescue those in danger.

- Important medical exceptions to this are GPs in certain situations and hospital doctors while at work.

- Suspension from duty may not absolve you of a duty of care towards patients.

have foreseeability of his failure to act. Again, it is arguable that if he does nothing and the patient comes to some harm as a result of this omission he might be held negligent. The author would argue that despite his suspension he does have sufficient legal proximity and forseeability for a duty of care to be established which is probably fair in all the circumstances. It would be extremely difficult to justify walking away from this patient without attempting resuscitation. It would be far easier to justify omission to act if the doctor did not know the patient. The legal proximity would effectively disappear. It is also interesting to ponder whether the hospital would supply indemnity for their suspended practitioner - one suspects not.

\section{THE ANSWER?}

Much of the above may seem far fetched, but many medicolegal cases arise from the most unlikely and unexpected situations.

So, what should a suspended doctor do when his actions might save a patient's life? Legal arguments apart, there must a strong moral and ethical imperative to act in the immediate interests of the patient. This argument is not solely derived from the principle that the doctor is a medical practitioner, but more from the fact that he is a compassionate human being. Most of us in this situation would hopefully put our fears of litigation to one side and attempt to help the patient. After all, it is generally unlikely that we will make matters worse, which is the legal requirement. This said, we must always be mindful that as medical practitioners we are at risk of litigation, both civil and criminal, and even when suspended from duty must be cautious of our duty of care.

\section{REFERENCES}

1 Carlisle D. The human cost of the suspension scandal. BMA News 25 January 2003.

2 Caparo Industries plc v Dickman [1990] 2 WLR 358.

3 Donoghue v Stevenson [1932] AC562.

4 R v Prentice, Sulman, Adomako and Holloway [1993] 4 All ER 877.

5 Bolam v Friern Hospital Hospital Managemant Committee [1957] 2 All ER 118. 